\title{
Sobre la distribución de Glaciares Rocosos en Chile, análisis de la situación y reconocimiento de nuevas localizaciones
}

\author{
About rock glaciers distribution in Chile: Situation analysis and new \\ locations recognition
}

\author{
Francisco J. Ferrando A.
}

\begin{abstract}
Resumen
La existencia de glaciares rocosos en diversas regiones de Chile ha sido indistintamente reconocida por algunos inventarios y no considerada por otros. Estudios particulares han revelado desde mediados del siglo XX su presencia en diferentes lugares del país. Pero, tanto estos como los inventarios distan aun de expresar la real extensión areal de su distribución así como de sus características o del volumen de recurso hídrico que representan. Por tanto, el objetivo de esta contribución es aportar al conocimiento de la real distribución de los glaciares rocosos en Chile. Con este fin se revisan antecedentes sobre la existencia de glaciares rocosos en la Cordillera de los Andes de Chile, sobre el conocimiento actual de su distribución zonal y regional, y se ratifica la presencia de ellos en unos casos, y su evolución en otros desde que fueron descritos y cartografiados por primera vez. Finalmente, mediante imágenes satelitales se reconocen glaciares rocosos no identificados previamente en las regiones de Atacama, Maule, Aysén y Magallanes, lo que se suma a otros recientemente informados en la región de Valparaíso. De entre ellos, resaltan los glaciares rocosos descubiertos en el Parque Nacional Torres del Paine, entre los $50^{\circ} 56^{\prime}$ y $50^{\circ} 58^{\prime}$ de latitud S, constituyendo evidencia de los efectos del cambio climático, especialmente de la tendencia térmica regional.

Como resultado, se establece la presencia de glaciares rocosos con diferentes tipologías y estados evolutivos, en sectores andinos y volcánicos a latitudes menores y mayores que las indicadas en estudios previos, lo que viene a aportar al conocimiento sobre estas expresiones de permafrost en Chile y al inventario nacional de glaciares.
\end{abstract}

Palabras claves: Glaciares rocosos, distribución zonal y regional, cambio climático

\begin{abstract}
The existence of Rocky glaciers in various regions of Chile has been equally recognized by some inventory and not seen by others. Particular studies have revealed its presence in different parts of the country since the mid-20th century. But both these as inventories are far from even expressing real areal extension of distribution as well as characteristics or the volume of water resources that represent. So, the goal of this research is increase the knowledge about the real rock glacier distribution in Chile. In this work we review background information on the existence of Rocky glaciers in the Cordillera of the Andes of Chile, the current knowledge of its zonal and regional distribution. Also, confirms the presence of them in some cases, and its evolution in others since they were described and mapped for the first time.

Finally recognize Rocky glaciers not previously identified in the regions of Atacama, Maule, Aysén and Magallanes, which joins other recently reported in the region of Valparaiso.

Among them, highlight the Rocky glaciers discovered in the Torres del Paine National Park, between $50^{\circ}$ $56^{\prime}$ and $50^{\circ} 58^{\prime}$ of southern latitude, constituting evidence of the effects of climate change, especially the regional thermal tendency.

How results, the existence of different types of rock glaciers and the evolution state of them is stablished in a more wide latitudinal distribution, increasing the actual knowledge and contributing to glacier inventories.
\end{abstract}

Keywords: Rock glaciers, zonal and regional distribution, climate change.

Recibido el 08 de agosto de 2017, aceptado el 01 de diciembre de 2017.

1 Depto. de Geografía, Facultad de Arquitectura y Urbanismo, Universidad de Chile. Avda. Portugal 84, Santiago. E-mail: fferrand@uchilefau.cl 


\section{Introducción}

La distribución de los Glaciares Rocosos en Chile, así como de la presencia de permafrost andino, aún no está completamente establecida dada la escasa investigación en este tema. La incorporación de este tipo de cuerpos detrítico-gélidos en los inventarios oficiales es reciente, siendo su conocimiento escaso a nivel de meso y micro-detalle. Por otro lado, se sabe de informes técnicos sobre la presencia de glaciares rocosos en distintos sectores del país, los que son de propiedad de empresas mineras nacionales y extranjeras, por lo que dicha información lamentablemente no es de dominio oficial y menos público.

Paralelamente, el conocimiento sobre los diferentes orígenes y tipos de glaciares rocosos en el país presenta poco desarrollo, y es solo con estudios a partir de la década de los 90's que se retoma el tema y se registra avance del conocimiento a nivel nacional.

En ese contexto, este trabajo se orienta a establecer la presencia de glaciares rocosos que, con diferentes tipologías y en distintos estados de evolución, existen en otros sectores andinos y volcánicos, como una contribución al inventario nacional de glaciares.

\section{Materiales y métodos}

Los resultados alcanzados en este trabajo se basan en el análisis de la información sobre glaciares rocosos y cubiertos existente desde mediados del siglo XX, obtenida inicialmente de la interpretación de fotos aéreas Trimetrogon del año 1945 (Lliboutry, 1956), de vuelos aerofotogramétricos posteriores y de reconocimiento directo en terreno, así como de cartogramas, antecedentes que son contrastados con los resultados del reconocimiento glaciológico efectuado en imágenes satelitales de acceso libre utilizadas en las composiciones del software Google Earth (Landsat/ Copernicus; CNES/Airbus; Digital Globe) tanto en el plano horizontal como en los DEM interactivos, y de algunas constataciones directas en terreno.

\section{Resultados}

\section{Análisis de antecedentes}

Actualmente sólo algunos inventarios glaciológicos consideran dentro de ellos a los glaciares rocosos. Tal es el caso de la información sobre Inventarios de Glaciares de Chile recopilada por Rivera, Casassa, Acuña, \& Lange, (2000) y Rivera (2002). Basados en información de diversas fuentes, en ellos no se estableció existencia de glaciares rocosos para las regiones del Norte Grande (I y II), del Norte Chico (III y IV) y para las cuencas de los ríos Aconcagua (Región de Valparaíso), Maipo (Región Metropolitana), Maule (Región del Maule), Itata (Región del Biobío), Chamiza (Región de Los Lagos). Tampoco indicó presencia de glaciares rocosos en las regiones de Aysén y Magallanes, ya que los inventarios correspondientes se refieren fundamentalmente a los Campos de Hielo Norte (CHN) y Sur (CHS) y a sus alrededores.

Sin embargo, en otros inventarios realizados se ha reconocido su existencia y/o se ha inventariado este tipo de glaciares. Tal es el caso de las cuencas de ríos como la del Río Copiapó (Vivero, 2008; Ulloa, García, Amigo, \& Milana, 2015); Río Huasco (Nicholson et al., 2009); Río Aconcagua (Bown, Rivera, Acuña, 2008); Río Maipo (Marangunic, 1977); y en el Río Mataquito (Noveroy, 1987). En las nacientes del Río Colorado, cuenca del Río Maipo, se está actualizando el inventario de glaciares rocosos en base a nuevas tecnologías de detección (Santibañez, 2017).

En el caso de la cuenca del Río Aconcagua, se ha determinado la existencia de 40,4 
$\mathrm{km}^{2}$ de glaciares cubiertos y $81 \mathrm{~km}^{2}$ de hielo sucio (glaciar semicubierto), no diferenciándose tipología ni indicándose número ni estimado el volumen de hielo. Una actualización en proceso ya ha reconocido alrededor de 700 glaciares rocosos, lo que se complementa con aquellos inventariados en el Río Putaendo, afluente del primero, donde recientemente se han distinguido, clasificado y descrito glaciares rocosos de diferentes tipos en más de 40 cabeceras de microcuencas (Fernández \& Ferrando, 2017; Ferrando \& Bellisario, 2017).

Aportes históricos aislados corresponden a Lliboutry (1956), Lliboutry, González, Simken (1958), Paskoff (1970), Wilgat, Kosik, Wojcirchowski (1970) y Marangunic (1976).

Más recientemente se encuentra información al respecto de glaciares rocosos en Ferrando (1996), Payne (1998), Ferrando (2003a, 2003b, 2003c); Ferrando, Soto, Vieira,
Lange, \& Quinteros, (2003); Brenning (2003); Soto, Ferrando, Vieira (2002); Brenning et al. (2009, 2010); Azócar y Brenning (2010); Ferrando (2012, 2014); Ferrando, Janke, Bellisario (2015); Janke, Bellisario, Ferrando (2015); Monnier \& Kinnard (2013, 2015a, 2015b, 2015c), entre otros.

\section{Distribución y zonificación}

Aparte de la distribución altitudinal planteada por Barsch $(1978,1996)$ para el permafrost de los andes áridos y Brenning (2003) para un sector del Valle del Río Yeso (Cuenca del Río Maipo), las primeras indicaciones sobre la distribución latitudinal de los glaciares rocosos en Chile se presentan en Brenning (2005). Según este estudio, la presencia de glaciares rocosos a lo largo de los Andes de Chile iría desde los $27^{\circ} 00^{\prime} \mathrm{S}$ (Río Copiapó) hasta los $35^{\circ} 25^{\prime} \mathrm{S}$ aproximadamente, en la cuenca del Río Maule, al oriente de la ciudad de Talca (figura 1).

Upper and lower limits of rock glacier distribution along a north-south profile of the Chilean Andes, and specific densities of rock glaciers within latitudinal-altitudinal strata.

Rock glacier density south of $33^{\circ} \mathrm{S}$ is based on Brenning (2005b). Rock glacier distribution limits modified after Brenning (2005b).
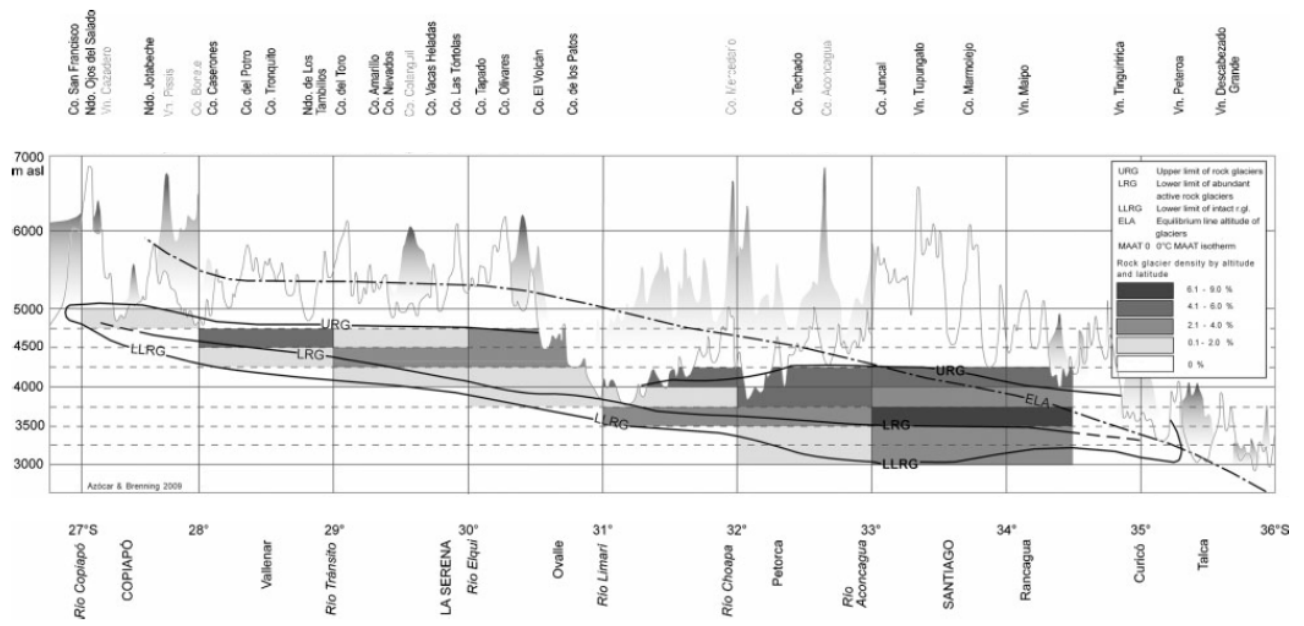

Figura 1. Distribución latitudinal y altitudinal de los glaciares rocosos en Chile según Brenning (2005).

Figure 1. latitudinal and altitudinal distribution of rock glaciers in Chile Brenning (2005). 
Posteriormente, en Brenning, Azócar, et al. (2010) se establece la distribución de los glaciares rocosos en los Andes de Chile, la cual se daría en tres zonas latitudinales:

Zona 1: Los Andes tropicales secos al $\mathrm{N}$ de la diagonal árida de Sudamérica $\left(15^{\circ} 00^{\prime} \mathrm{S}\right.$ a $23^{\circ} 30^{\prime} \mathrm{S}$ )

Zona 2: La zona árida a sub-húmeda del área extra tropical con lluvias invernales $\left(27^{\circ} 00^{\prime} \mathrm{S}\right.$ a $\left.35^{\circ} 25^{\prime} \mathrm{S}\right)$, que se corresponde con la figura 1

Zona 3: Localmente en la parte oriental relativamente seca de los Andes patagónicos (aproximadamente $45^{\circ} \mathrm{S}$ a $\left.50^{\circ} \mathrm{S}\right)$

Por su parte, según la Dirección General de Aguas del Ministerio de Obras Públicas (MOP-DGA) (2009), los glaciares rocosos, los que representarían una fracción muy pequeña de los glaciares de Chile en términos de área y volumen, presentan un número importante en la Zona Norte del país correspondiendo a cuerpos activos e inactivos que se localizan principalmente en las laderas de la Cordillera Andina del río Copiapó y Choapa, así como más al norte, en los volcanes San Pedro y San Pablo ( $\left.21^{\circ} 53^{\prime} \mathrm{S}\right)$.

Contradictoriamente en el mismo documento y para la Zona Centro se indica que "los glaciares de escombros activos del Cajón de la Casa de Piedra, en el valle del Río Yeso, cuenca del Río Maipo, almacenan más agua que los glaciares descubiertos y que esta relación puede ser considerada como representativa para muchas cuencas pequeñas de la Cordillera de Santiago con altitudes menores a los $5.000 \mathrm{~m}$ (Ministerio de Obras Públicas, 2009).

En esta misma fuente y para la zona austral, se indica que no se han detectado glaciares de este tipo, no obstante existir una importante superficie de glaciares parcialmente recubiertos, en particular debido a la presencia de volcanes activos, que han generado grandes cantidades de lava y cenizas volcánicas, las que se han depositado sobre algunos glaciares, destacándose los del Volcán Chillán, Llaima y Villarrica (Rivera, 1989; Rivera et al., 2006), Volcán Michinmahuida (Masiokas et al., 2009), y en parte por el arrastre de material morrénico (Aniya et al., 2007).

Destacan también como glaciares con importante recubrimiento, los Glaciares Exploradores y Grosse ubicados en la ladera norte del CHN (Rivera, Casassa, Acuña, Lange, 2007) y el Glaciar Frías en el CHS (Rivera \& Casassa, 2004).

\section{Situación de glaciares rocosos}

\section{Región de Antofagasta.}

En esta región, en los volcanes San Pedro y San Pablo, Payne (1998) describe un glaciar de roca activo que alcanza una altitud mínima de $4.525 \mathrm{~m}$. Al respecto, el análisis de imágenes satelitales Landsat 2016 indica la presencia de solo dos glaciares rocosos en este complejo volcánico, ambos en la ladera SE del Volcán San Pedro, uno a continuación del otro, con un cierto grado de superposición, y orientados hacia el S (figura 2).

El superior se extiende entre $4.904 \mathrm{y}$ 4.749 m.s.n.m. y presenta características morfológicas tanto en su superficie (cordones y surcos) como frontales (escarpe de derrumbamiento), las que evidencian actividad. El segundo se reconoce entre 4.764 y $4.647 \mathrm{msnm}$, y sus características morfológicas indican inactividad, pudiendo ser catalogado de glaciar rocoso fósil o glaciar de escombros (tabla 1). Estos glaciares rocosos están dentro de la Zona 1 de Brenning, Azócar, et al. (2010). 
Tabla 1

Glaciares rocosos en la falda sur del Volcán San Pedro, Región de Antofagasta, Chile.

Table 1

Rock glaciers in the southern slope of the San Pedro Volcano, Antofagasta region, Chile

\begin{tabular}{|c|c|c|c|c|c|c|c|}
\hline \multirow{2}{*}{$\begin{array}{l}\text { Identificación } \\
\text { del Glaciar }\end{array}$} & \multicolumn{2}{|c|}{ Coordenadas centrales } & \multirow{2}{*}{$\begin{array}{r}\text { H máx } \\
(\mathrm{msnm})\end{array}$} & \multirow{2}{*}{$\begin{array}{r}\mathrm{H} \text { min } \\
(\mathrm{msnm})\end{array}$} & \multirow{2}{*}{$\begin{array}{l}\text { Largo } \\
\text { total } \\
(\mathrm{km})\end{array}$} & \multirow{2}{*}{$\begin{array}{r}\text { Ancho } \\
\text { medio } \\
(\mathrm{km})\end{array}$} & \multirow{2}{*}{$\begin{array}{r}\text { Orientación } \\
\text { general }\end{array}$} \\
\hline & Latitud Sur & $\begin{array}{r}\text { Longitud Oeste } \\
\text { (W) }\end{array}$ & & & & & \\
\hline VSP-1 (activo) & $21^{\circ} 54^{\prime} 25^{\prime \prime}$ & $68^{\circ} 22^{\prime} 45^{\prime \prime}$ & 4904 & 4749 & 0.72 & 0.17 & $\mathrm{~S}$ \\
\hline VSP-2 (fósil) & $21^{\circ} 54^{\prime} 37^{\prime \prime}$ & $68^{\circ} 22^{\prime} 41^{\prime \prime}$ & 4764 & 4647 & 0.64 & 0.14 & S \\
\hline
\end{tabular}

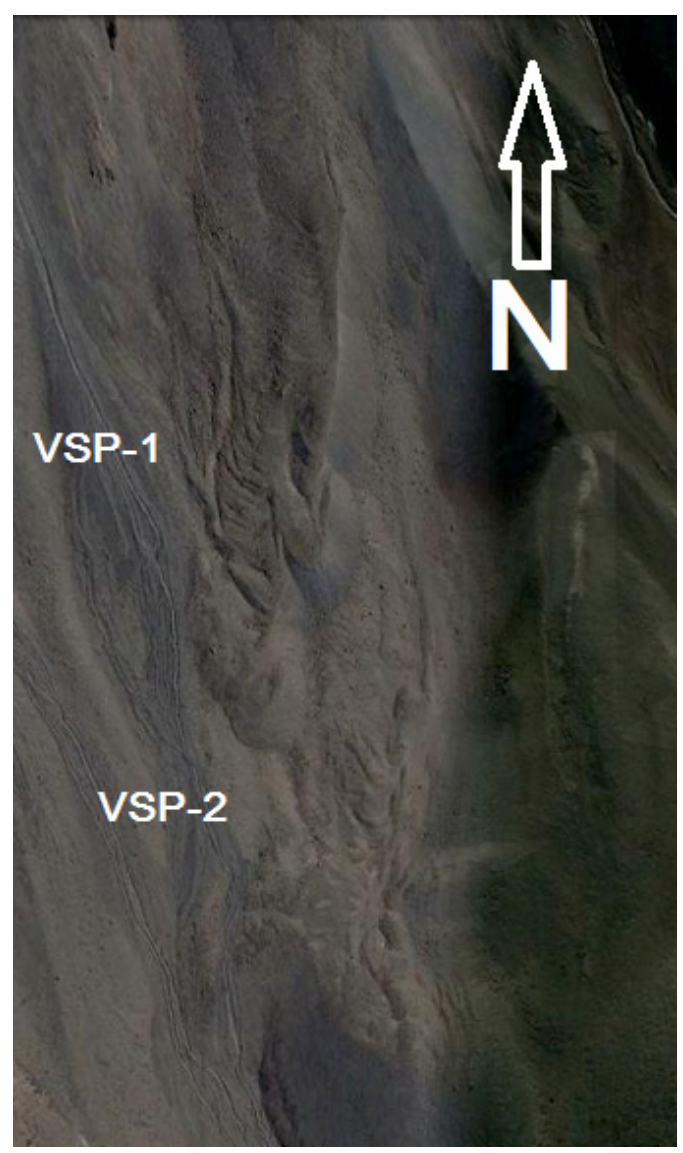

Figura 2. Pequeños glaciares rocosos en la ladera sur este del Volcán San Pedro, Región de Antofagasta, Chile, a los $21^{\circ} 54^{\prime} 30^{\prime}$ S (Subescena de imagen Landsat 2016)

Figure 2. Little rock glaciers located in the south-east slope of the San Pedro Volcano, Antofagasta Region, at 2154'30"'S (Subescena de imagen Landsat 2016)

Otras formas reconocidas en las laderas de estos volcanes y que semejan glaciares rocosos, en realidad corresponden a pequeñas coladas de lava circunscritas a los faldeos volcánicos con el típico frente de derrumbamiento que caracteriza los talus rock glaciers criogénicos. 
Región de Los Lagos.

En esta región, en el caso del Volcán Tronador

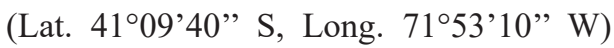
de los glaciares rocosos señalados por Lliboutry (1956) en su cartografía a escala 1:250.000, distinción basada en fotos aéreas Trimetrogon del año 1945 (figura 3), y por Bown (2004) como glaciares recubiertos, al 2017 solo quedan tres, siendo el de mayor superficie el de la ladera sur (Glaciar Verde) (figura 4 y tabla 2).
El Glaciar Casa Pangue indicado en la figura 3 con dimensiones considerables en 1945 $(5,6 \mathrm{~km})$, hoy en día está reducido a una extensión de solo $2,64 \mathrm{~km}$. Igual situación presenta el Ventisquero Negro, lengua que baja hacia el sector de Pampa Linda (Río Manso), y que habría tenido una extensión de 5,7 km. Hoy en día tiene solo 1,61 km y culmina en una laguna proglacial.

Por su parte, ya no existen los pequeños glaciares rocosos que descendían hacia el Rio Frías y el Río Alerce, ambos en Argentina, y hacia el Río Blanco Chico en Chile.

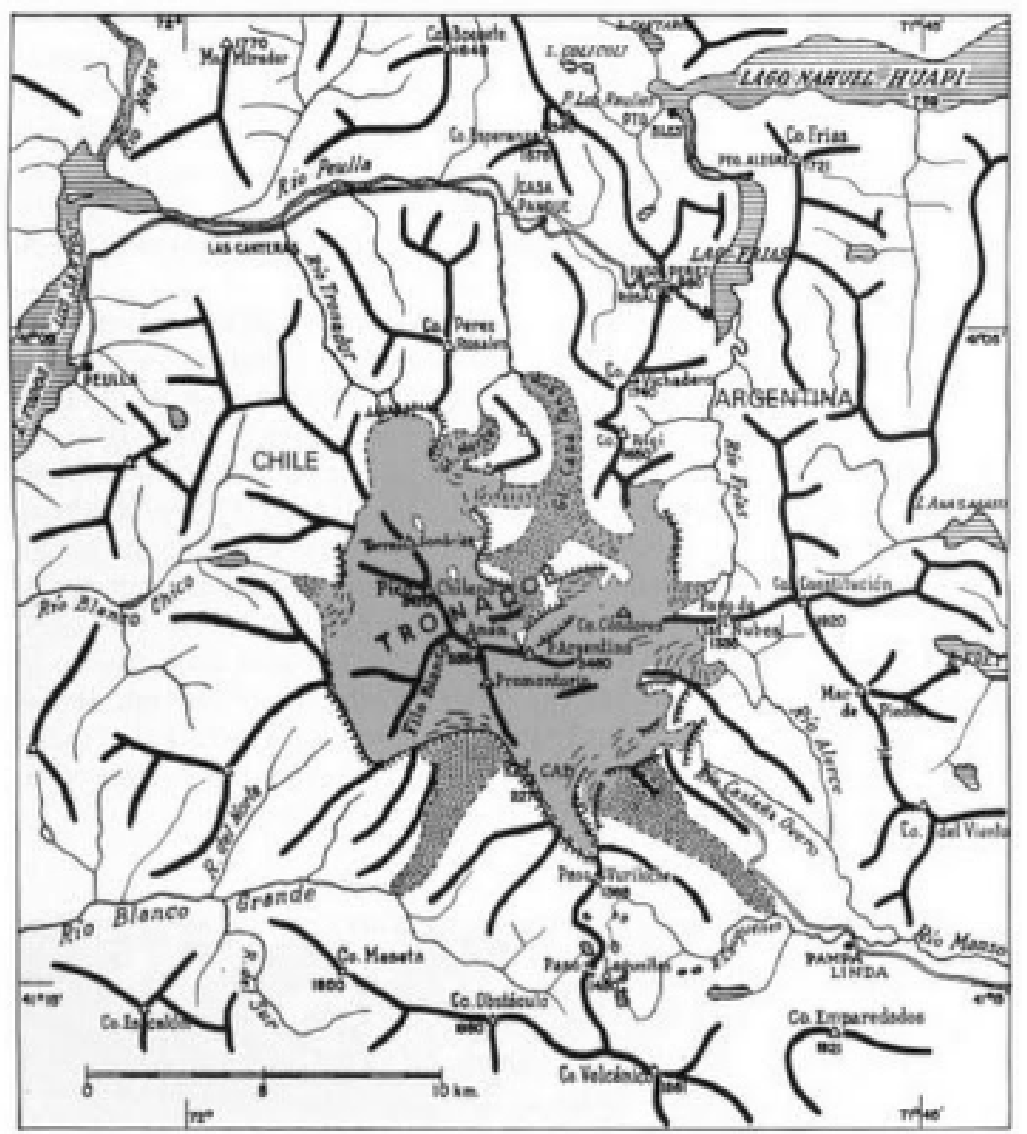

Figura 3. Glaciares rocosos en el Volcán Tronador según Lliboutry (1956)

Figure 3. Rock glaciers at the Tronador Volcano according to Lliboutry (1956) 


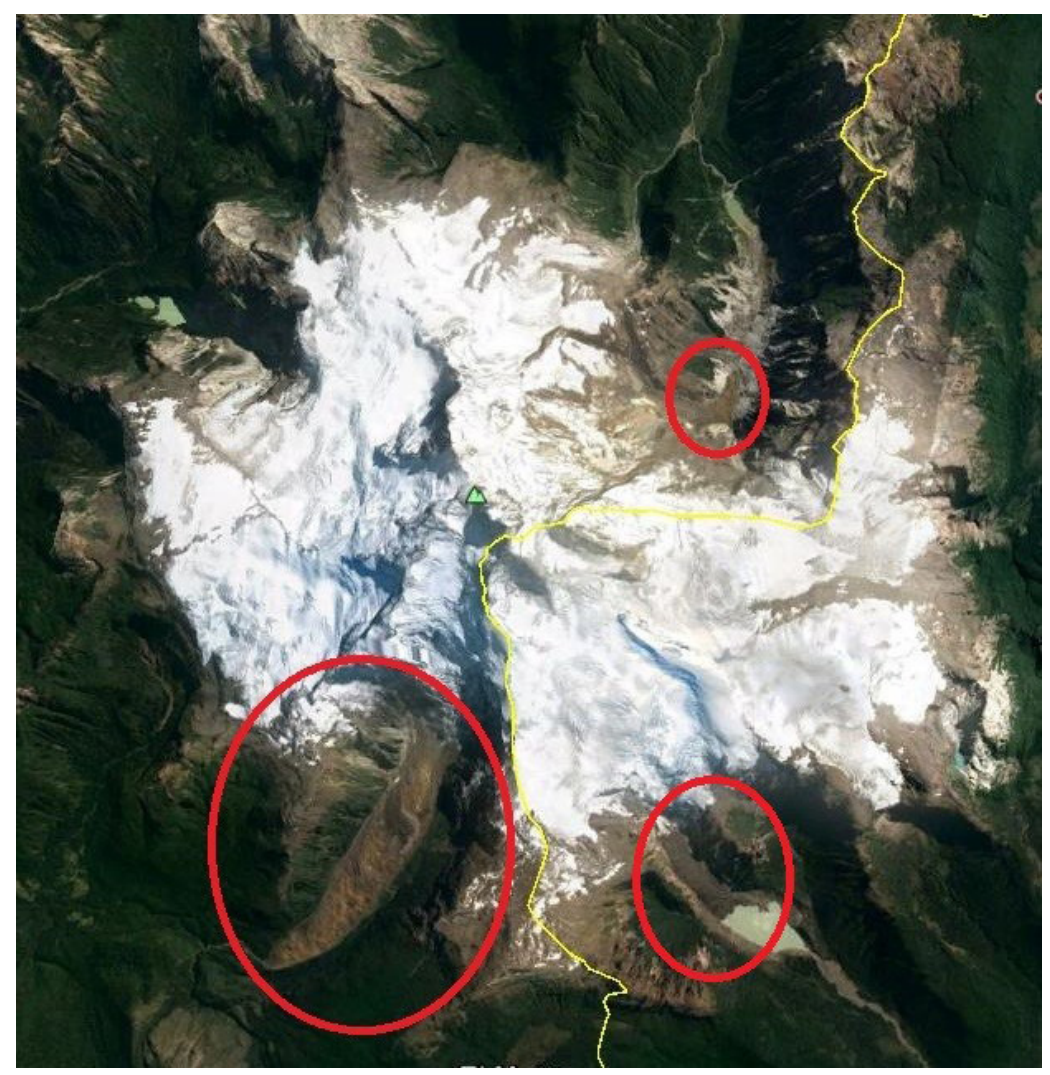

Figura 4. Glaciares rocosos actuales en el Volcán Tronador, Cordillera de los Andes de la Región de Los Lagos. La línea amarilla indica el límite entre Chile y Argentina (Imagen 2017 CNES/Airbus).

Figure 4. Nowadays rock glaciers at the Tronador Volcano, Andean Range of the Los Lagos region. Yellow line indicates international frontier between Chile and Argentina (Imagen 2017 CNES/

$$
\text { Airbus). }
$$

Tabla 2

Actuales glaciares rocosos en el Volcán Tronador.

Table 2

Nowadays rock glaciers at Tronador volcano.

\begin{tabular}{|c|c|c|c|c|c|c|c|}
\hline \multirow{2}{*}{$\begin{array}{l}\text { Identificación } \\
\text { del Glaciar }\end{array}$} & \multicolumn{2}{|c|}{ Coordenadas centrales } & \multirow{2}{*}{$\begin{array}{r}\text { H máx } \\
(\mathrm{msnm})\end{array}$} & \multirow{2}{*}{$\begin{array}{r}\mathrm{H} \text { min } \\
(\mathrm{msnm})\end{array}$} & \multirow{2}{*}{$\begin{array}{r}\text { Largo } \\
\text { total } \\
(\mathrm{km})\end{array}$} & \multirow{2}{*}{$\begin{array}{r}\text { Ancho } \\
\text { medio } \\
(\mathrm{km})\end{array}$} & \multirow{2}{*}{$\begin{array}{r}\text { Orientación } \\
\text { general }\end{array}$} \\
\hline & Latitud Sur & $\begin{array}{r}\text { Longitud Oeste } \\
\text { (W) }\end{array}$ & & & & & \\
\hline $\begin{array}{l}\text { Glaciar Casa } \\
\text { Pangue } \\
\text { (Tronador-N) }\end{array}$ & $41^{\circ} 08^{\prime} 10^{\prime \prime}$ & $71^{\circ} 51^{\prime} 45^{\prime \prime}$ & 1231 & 830 & 2.64 & 0.31 & E y N \\
\hline $\begin{array}{l}\text { Glaciar Verde } \\
\text { (Tronador-S) }\end{array}$ & $41^{\circ} 12^{\prime} 23^{\prime \prime}$ & $71^{\circ} 54^{\prime} 19^{\prime \prime}$ & 1458 & 991 & 4.73 & 0.71 & $\mathrm{~S}$ \\
\hline $\begin{array}{l}\text { Glaciar Negro } \\
\text { (Ar.) }\end{array}$ & $41^{\circ} 11^{\prime} 55^{\prime \prime}$ & $71^{\circ} 50^{\prime} 55^{\prime \prime}$ & 1306 & 1073 & 1.61 & 0.42 & SE \\
\hline
\end{tabular}




\section{Reconocimiento de nuevos glaciares rocosos}

En la Región de Atacama, producto de una revisión acuciosa e interpretación de imágenes satelitales, se reconoce la existencia por el norte de un glaciar rocoso en la latitud $27^{\circ} 47^{\prime} \mathrm{S}$, longitud $69^{\circ} 20^{\prime} \mathrm{W}$, a una altitud de $5.447 \mathrm{msnm}$, dentro de la Zona 2 establecida por Brenning, Bodin, et al. (2010). Por toponimia local aquí se le denomina Aguas Blancas (figura 5 y tabla 3). Sin embargo, no se reconocen otros glaciares rocosos más al $\mathrm{N}$ de esta latitud dentro de esta Zona.

Tabla 3

Datos del Glaciar Rocoso Aguas Blancas.

Table 3

Aguas Blancas rock glacier data.

\begin{tabular}{|c|c|c|c|c|c|c|c|}
\hline \multirow{2}{*}{$\begin{array}{l}\text { Identificación } \\
\text { del Glaciar }\end{array}$} & \multicolumn{2}{|c|}{ Coordenadas centrales } & \multirow{2}{*}{$\begin{array}{l}\text { H máx } \\
(\mathrm{msnm})\end{array}$} & \multirow{2}{*}{$\begin{array}{l}\mathrm{H} \min \\
(\mathrm{msnm})\end{array}$} & \multirow{2}{*}{$\begin{array}{r}\text { Largo } \\
\text { total } \\
(\mathrm{km})\end{array}$} & \multirow{2}{*}{$\begin{array}{l}\text { Ancho } \\
\text { medio } \\
(\mathrm{km})\end{array}$} & \multirow{2}{*}{$\begin{array}{r}\text { Orientación } \\
\text { general }\end{array}$} \\
\hline & Latitud Sur & $\begin{array}{r}\text { Longitud Oeste } \\
(\mathrm{W})\end{array}$ & & & & & \\
\hline Aguas Blancas & $27^{\circ} 47^{\prime} 56^{\prime \prime}$ & $69^{\circ} 20^{\prime} 49^{\prime \prime}$ & 4871 & 4636 & 1,45 & 0,50 & SSW \\
\hline
\end{tabular}

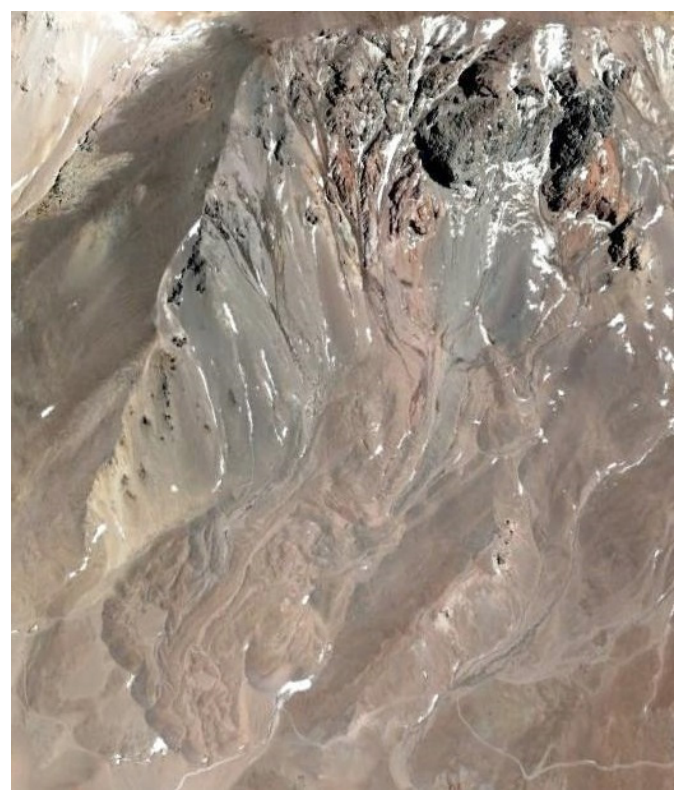

Figura 5. Glaciar rocoso del sector de Aguas Blancas. Fuente: Image 2017 Digital Globe.

Figure 5. Aguas Blancas rock glacier. Source: Image 2017 Digital Globe.

La morfología de superficie de este glaciar rocoso se presenta irregular, carente de signos de actividad y una lengua central correspondiente a un depósito fluidal del tipo debris flow, el cual por el grado de intemperismo de los materiales es tan antiguo como el material morrénico del glaciar. Dado que se encuentra en una zona que registra precipitación nival estacional, se asume la posibilidad de presencia de 
núcleos de hielo (ice-core) dentro de la masa, por lo que no correspondería a un glaciar de escombros propiamente tal, sino más bien a la etapa de hielo intersticial, estado de transición entre un glaciar rocoso y uno fósil. Se observa, además, que se encuentra superpuesto a otro glaciar rocoso más antiguo y algo más extenso, cuyo pie está marcado por el trazado de un camino local.

En la Región del Maule, en la latitud $36^{\circ} 07^{\prime}$ $\mathrm{S}$, longitud $71^{\circ} 01^{\prime} \mathrm{W}, \mathrm{y}$ algo más al $\mathrm{S}$ de la Zona 2, en el Cajón de Olla Seca se reconoce una forma que podría corresponder a un glaciar rocoso, el cual presenta una morfología superficial del tipo estructura de flujo (Brenning, Long, Fieguth, 2012) en su manto detrítico superficial, lo cual podría evidenciar la ocurrencia de fenómenos de surging también en glaciares rocosos.

En este último se reconoce un arco morrénico morfológicamente modificado en su frente y mejor conservado en sus costados. Al pie de la morrena frontal se presenta una laguna proglacial, probablemente alimentada por aguas de fusión de ice-core remanentes. (figura 6 y tabla 4)

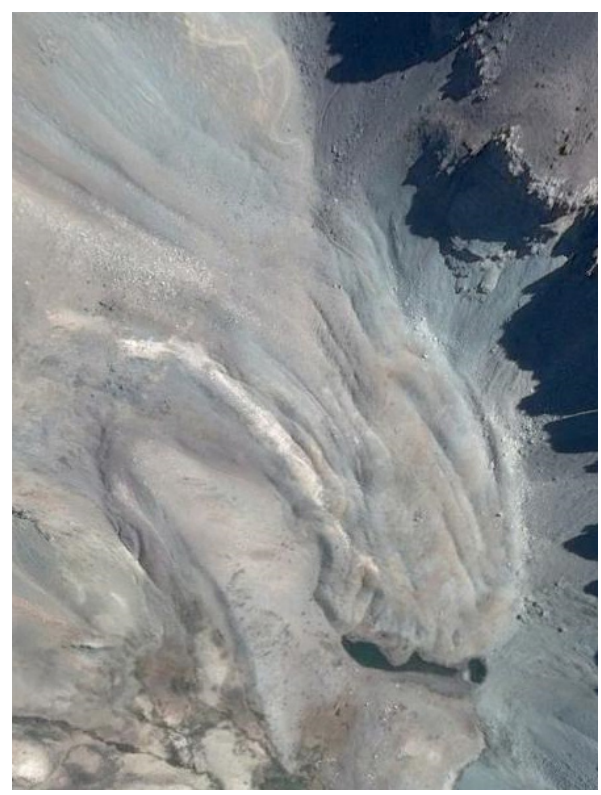

Figura 6. Glaciar rocoso de Cajón de Olla Seca Fuente: Image CNES 2017/Airbus.

Figure 6. Olla Seca rock glacier Source: Image CNES 2017/Airbus.

Tabla 4

Datos del Glaciar Rocoso Olla Seca.

Table 4

Olla Seca rock glacier data.

\begin{tabular}{|c|c|c|c|c|c|c|c|}
\hline \multirow{2}{*}{$\begin{array}{l}\text { Identificación } \\
\text { del Glaciar }\end{array}$} & \multicolumn{2}{|c|}{ Coordenadas centrales } & \multirow{2}{*}{$\begin{array}{r}\text { H máx } \\
(\mathrm{msnm})\end{array}$} & \multirow{2}{*}{$\begin{array}{r}\mathrm{H} \text { min } \\
(\mathrm{msnm})\end{array}$} & \multirow{2}{*}{$\begin{array}{r}\text { Largo } \\
\text { total } \\
(\mathrm{km})\end{array}$} & \multirow{2}{*}{$\begin{array}{r}\text { Ancho } \\
\text { medio } \\
(\mathrm{km})\end{array}$} & \multirow{2}{*}{$\begin{array}{r}\text { Orientación } \\
\text { general }\end{array}$} \\
\hline & Latitud Sur & $\begin{array}{r}\text { Longitud Oeste } \\
\text { (W) }\end{array}$ & & & & & \\
\hline G1. Olla Seca & $36^{\circ} 06^{\prime} 53^{\prime \prime}$ & $71^{\circ} 01^{\prime} 07^{\prime \prime}$ & 2.224 & 2088 & 0,74 & 0,27 & SSE \\
\hline
\end{tabular}


En la Región de Aysén, el Volcán Corcovado se ubica a los $43^{\circ} 11^{\prime} 39^{\prime \prime}$ de latitud S, unos dos grados más al $\mathrm{N}$ de la Zona 3 definida por Brenning, Azócar, et al. (2010)

Este volcán, el cual nació en la parte media de valles glaciales generando cuencas lacustres endorreicas, presenta su cumbre de 1720 m.s.n.m. y gran parte de sus empinadas laderas cubiertas de hielo. En su ladera sur se presentan dos circos y valles glaciales, los que albergan glaciares blancos. La parte media-inferior del mayor de ellos (4,7 km de largo) y a su vez, el más occidental, registra entre los 804 y los 675 msnm un proceso progresivo de fusión, el que está gradualmente llevando este glaciar descubierto a la situación de glaciar rocoso. Actualmente, la lengua de hielo, que tiene un ancho medio de $0,27 \mathrm{~km}$, se presenta cubierta de material morrénico en una extensión de 0,78 km de largo (figura 7 y tabla 5).

Tabla 5

Datos del Glaciar Corcovado-S. Solo se indican las altitudes y extensión del área cubierta del glaciar, el cual nace a 1710 m.s.n.m.

Table 5

Southern Corcovado rock glacier born al 1710 m.a.s.l. Data like altitude and extension of the covered area is indicated.

\begin{tabular}{lrrrrrrr}
\hline $\begin{array}{l}\text { Identificación } \\
\text { del Glaciar }\end{array}$ & \multicolumn{2}{c}{ Coordenadas centrales } & $\begin{array}{r}\mathrm{H} \text { máx } \\
(\mathrm{msnm})\end{array}$ & $\begin{array}{r}\mathrm{H} \text { min } \\
(\mathrm{msnm})\end{array}$ & $\begin{array}{r}\text { Largo } \\
\text { total } \\
(\mathrm{km})\end{array}$ & $\begin{array}{r}\text { Ancho } \\
\text { medio } \\
(\mathrm{km})\end{array}$ & $\begin{array}{r}\text { Orientación } \\
\text { general }\end{array}$ \\
\cline { 2 - 6 } Corcovado-S & $43^{\circ} 13^{\prime} 07^{\prime \prime}$ & $72^{\circ} 48^{\prime} 01^{\prime \prime}$ & 804 & 675 & 0,78 & 0,27 & $\mathrm{SW}$ \\
\hline
\end{tabular}

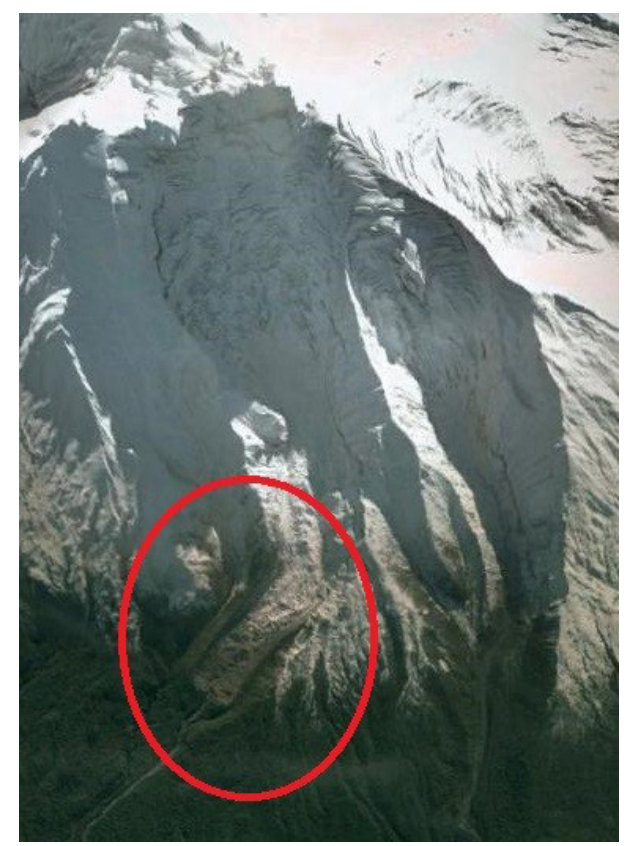

Figura 7. Glaciar Rocoso del Corcovado-S (Image 2017 Digital Globe).

Figure 7. Rock glacier at the southern slope of the Corcovado Volcano (Image 2017 Digital Globe). 
En la misma región, pero más al sur, se reconoce un glaciar cubierto en la vertiente meridional del Volcán Melimoyu a los $44^{\circ} 05^{\prime} \mathrm{S}$ y longitud 62 ${ }^{\circ} 50^{\prime} \mathrm{W}$ (Región de Aysén), entre los
1300 y 1090 m.s.n.m., el cual deriva de un glaciar blanco regenerado. Este se encuentra prácticamente un grado de latitud más al $\mathrm{N}$ de la Zona 3. (figura 8 y tabla 6 )

\section{Tabla 6.}

Datos del Glaciar Rocoso Melimoyu-S, subtipo cubierto, en ladera S del Volcán homónimo. Fuente: Elaboración propia (2017)

Table 6.

Melimoyu-S rock glacier data. Is a debris covered type locate at the southern volcano slope. Source: Own elaboration (2017)

\begin{tabular}{lccrrrrr}
\hline $\begin{array}{l}\text { Identificación } \\
\text { del Glaciar }\end{array}$ & \multicolumn{2}{c}{ Coordenadas centrales } & $\begin{array}{r}\text { H máx } \\
(\mathrm{msnm})\end{array}$ & $\begin{array}{r}\mathrm{H} \text { min } \\
(\mathrm{msnm})\end{array}$ & $\begin{array}{r}\text { Largo } \\
\text { total } \\
(\mathrm{km})\end{array}$ & $\begin{array}{r}\text { Ancho } \\
\text { medio } \\
(\mathrm{km})\end{array}$ & $\begin{array}{r}\text { Orientación } \\
\text { general }\end{array}$ \\
\hline $\begin{array}{c}\text { Glaciar Rocoso } \\
\text { Melimoyu-S }\end{array}$ & $4^{\circ} 05^{\circ}$ & $72^{\circ} 50^{\prime}$ & 1.300 & 1.090 & 0,91 & 0,28 & $\mathrm{~S}$ \\
\hline
\end{tabular}

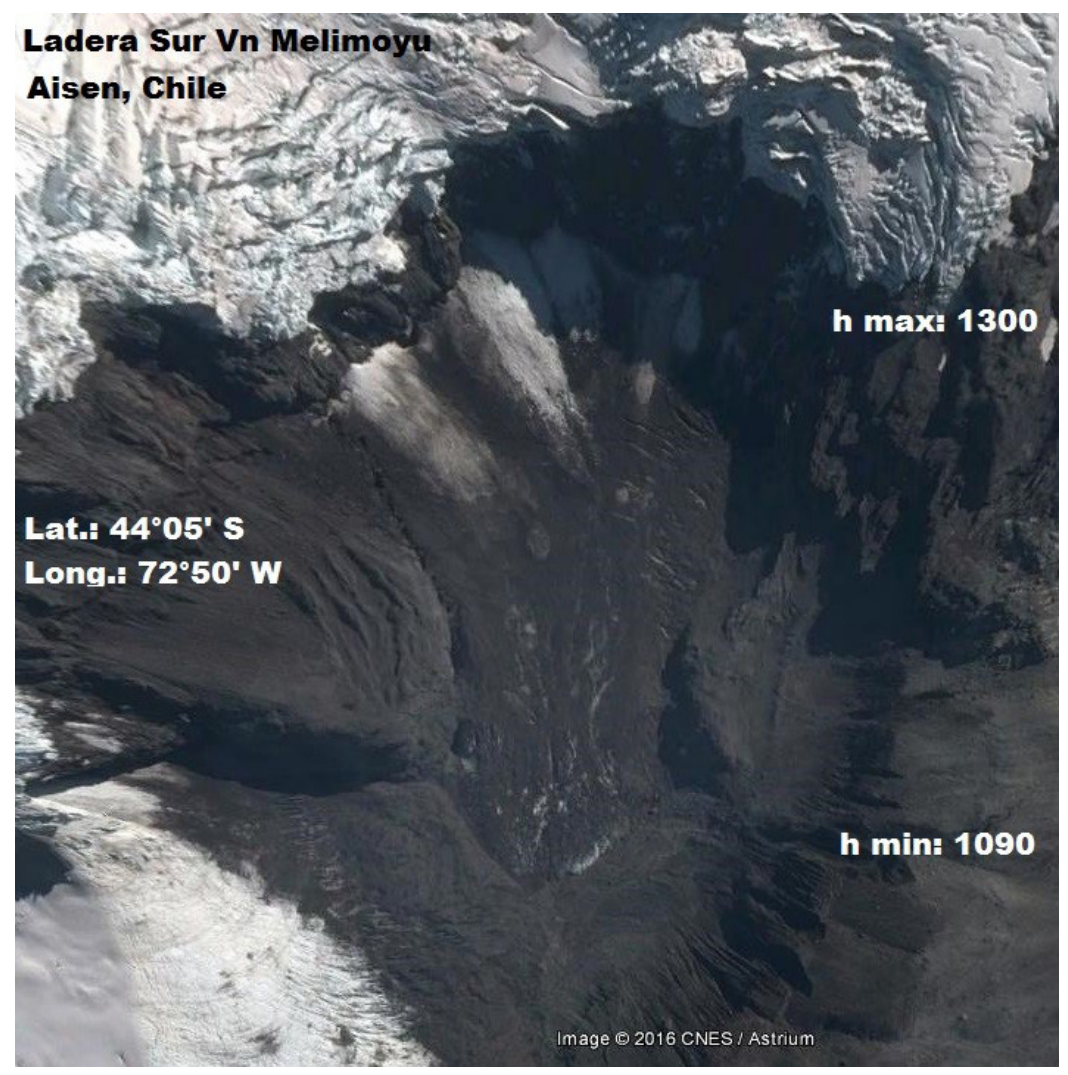

Figura 8. Glaciar rocoso cubierto con un manto morrénico de origen volcánico y de piroclastos en la ladera S del Volcán Melimoyu, Región de Aysén, Chile. Fuente: Image CNES/Airbus (2017)

Figure 8. Rock glacier covered by a volcanic debris mantle at the southern slope of Melimoyu volcano, Aysén region, Chile. Source: Image CNES/Airbus (2017) 
En la Región de Magallanes y la Antártica Chilena y al margen de lenguas de hielo que se están cubriendo progresivamente en los CHN y CHS, se da a conocer la existencia de varios glaciares rocosos hasta la fecha no reconocidos ni descritos en dos ubicaciones dentro del Parque Nacional Torres del Paine, en la Región de Magallanes: el Valle del Francés y el Valle del Silencio.
En el Valle del Francés se identifican seis lenguas de glaciares rocosos ubicados en su cabecera, todos de origen glacial pues derivan de glaciares blancos empotrados en las paredes de un circo glacial compuesto, lo que indicaría la existencia previa de un glaciar de tipo himalayo. También se distingue lo que podría ser una morrena con núcleo de hielo, varios arcos morrénicos frontales y morrenas laterales (figura 9).

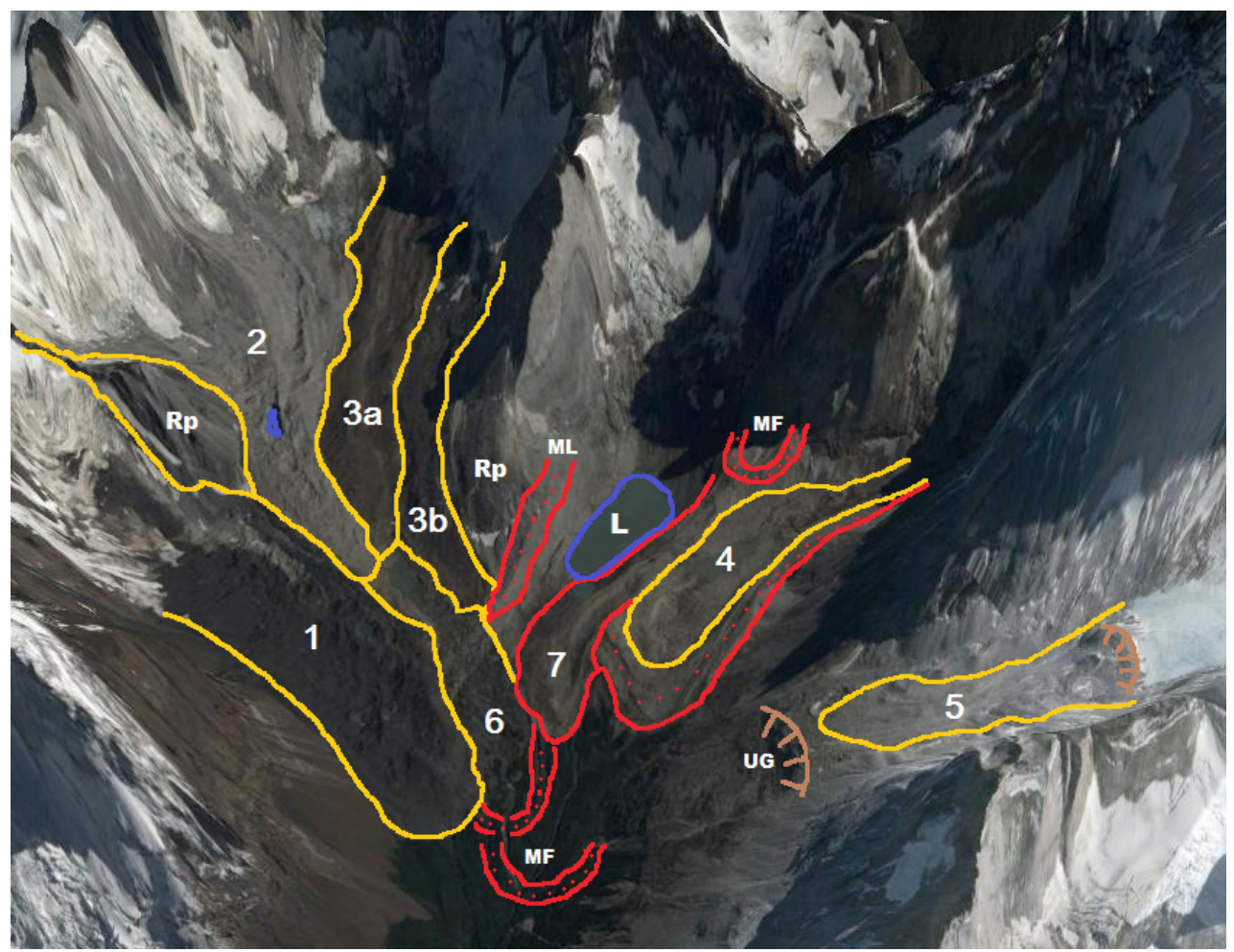

Figura 9. Glaciares rocosos en las nacientes del Valle del Francés, Parque Nacional Torres del Paine, Región de Magallanes. Fuente: Image CNES/Airbus (2017)

Figure 9. Rock glaciers at the head of the Valle del Francés, Torres del Paine National Park, Magallanes Region. Source: Image CNES/Airbus (2017)

La descripción glacio-morfológica de la figura 9, es la siguiente:

Los glaciares rocosos 1, 2, 3a, 3b y 4 tienen un origen glacial y presentan evidencias de termokarst (depresiones de colapso con lagunas y escarpes de subsidencia que dejan ver el hielo enterrado por el manto morrénico).
La lengua de Glaciar rocoso 5, de origen glacial, se ubica entre dos umbrales rocosos. Se observa el extremo de la lengua del glaciar blanco del cual deriva genéticamente.

La unidad 6 corresponde a un lecho rocoso con remanentes morrénicos gruesos y 
lagunas, al parecer afectado por GLOF relacionado con la laguna ubicada aguas arriba (L). En su extremo inferior existe un arco morrénico moderadamente bien conservado.

El número 7 identifica una forma sedimentaria que, dada su morfología, su posición y características, se considera a priori que correspondería a una morrena medial con núcleo de hielo (Ice core moraine).

También se distinguen e indican algunos arcos morrénicos frontales (MF), morrenas laterales (ML), umbrales glaciales (UG) y sectores de roca pulida $(\mathrm{Rp})$.

En el caso del Valle del Silencio se trata de un solo glaciar rocoso cuya lengua de hielo presenta claras evidencias de termokarst y lagunas supraglaciales en su sección inferior. Este glaciar rocoso representa el end member del continuum filogenético de un glaciar blanco que perdió sus características por un predominio de balance de masa negativo. Ello es evidente al reconocerse la decoupling zone en el contacto con la pared del circo glacial (figura 10).

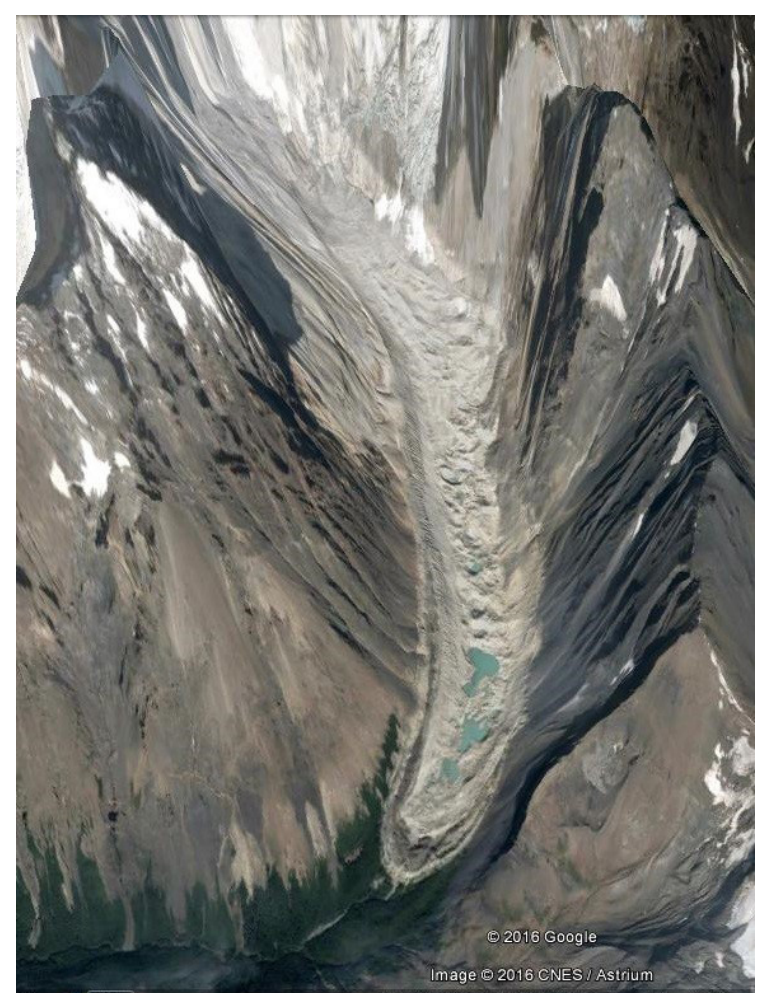

Figura 10. Glaciar rocoso del Valle del Silencio. Fuente: Elaboración propia (2017)

Figure 10. Valle del Silencio rock glacier. Source: Own elaboration (2017)

En el caso de este glaciar rocoso son claramente discernibles el arco morrénico frontal y la morrena lateral del costado derecho. En el costado izquierdo la actividad de desprendimiento de detritos parece mucho más activo observándose un conjunto de conos coluviales coalescentes, los cuales sepultan gran parte de la morrena lateral correspondiente. Solo en el extremo inferior derecho de la lengua se aprecia una parte de ella. 
También se observa un mínimo distanciamiento del frente respecto de la cobertura vegetacional, lo cual indica ausencia de movimientos de avance y retroceso durante al menos algunas décadas. Esta inactividad se ve corroborada por la morfología superficial del manto detrítico, la cual se presenta muy irregular, con depresiones derivadas de colapsos

\section{Tabla 7}

Glaciares Rocosos del Parque Nacional Torres del Paine, Región de Magallanes, Chile. Fuente: VF: Valle del Francés; ICM: Ice core moraine.

Table 7

Torres del Paine National Park rock glaciers, Magallanes Region, Chile. Source: VF: Valle del Francés; ICM: Ice core moraine.

\begin{tabular}{|c|c|c|c|c|c|c|c|}
\hline \multirow{2}{*}{$\begin{array}{l}\text { Identificación } \\
\text { del Glaciar }\end{array}$} & \multicolumn{2}{|c|}{ Coordenadas centrales } & \multirow{2}{*}{$\begin{array}{l}\text { H máx } \\
(\mathrm{msnm})\end{array}$} & \multirow{2}{*}{$\begin{array}{l}\mathrm{H} \text { min } \\
(\mathrm{msnm})\end{array}$} & \multirow{2}{*}{$\begin{array}{l}\text { Largo } \\
\text { total } \\
(\mathrm{km}) \\
\end{array}$} & \multirow{2}{*}{$\begin{array}{l}\text { Ancho } \\
\text { medio } \\
(\mathrm{km})\end{array}$} & \multirow{2}{*}{$\begin{array}{l}\text { Orientación } \\
\text { general }\end{array}$} \\
\hline & Latitud Sur & $\begin{array}{l}\text { Longitud Oeste } \\
\text { (W) }\end{array}$ & & & & & \\
\hline Del Silencio & $50^{\circ} 56^{\prime} 10^{\prime \prime}$ & $73^{\circ} 00^{\prime} 13^{\prime \prime}$ & 1.268 & 834 & 4,60 & 0,57 & N-E \\
\hline $\mathrm{VF}-1$ & $50^{\circ} 58^{\prime} 51^{\prime \prime}$ & $73^{\circ} 04^{\prime} 51^{\prime \prime}$ & 1.050 & 823 & 2,26 & 0,83 & $\mathrm{E}$ \\
\hline VF - 2 & $50^{\circ} 58^{\prime} 23^{\prime \prime}$ & $73^{\circ} 05^{\prime} 57^{\prime \prime}$ & 1.343 & 951 & 3,03 & 0,46 & SE a SSE \\
\hline$V F-3 a$ & $50^{\circ} 57^{\prime} 49^{\prime \prime}$ & $73^{\circ} 05^{\prime} 57^{\prime \prime}$ & 1.284 & 1.004 & 2,60 & 0,49 & SE \\
\hline$V F-3 b$ & $50^{\circ} 57^{\prime} 43^{\prime \prime}$ & $73^{\circ} 05^{\prime} 37^{\prime \prime}$ & 1.175 & 986 & 2,60 & 0,49 & SE \\
\hline VF - 4 & $50^{\circ} 57^{\prime} 42^{\prime \prime}$ & $73^{\circ} 03^{\prime} 26^{\prime \prime}$ & 1.146 & 880 & 2,36 & 0,84 & SSW a S \\
\hline VF - 5 & $50^{\circ} 58^{\prime} 09^{\prime \prime}$ & $73^{\circ} 02^{\prime} 00^{\prime \prime}$ & 1.524 & 1.196 & 1,82 & 0,45 & SW \\
\hline ICM-VF & $50^{\circ} 58^{\prime} 13^{\prime \prime}$ & $73^{\circ} 04^{\prime} 00^{\prime \prime}$ & 1.020 & 832 & 1,88 & 0,26 & $\mathrm{~S}$ a SE \\
\hline
\end{tabular}

Más al sur, en el Monte Burney (Lat. $52^{\circ} 20^{\prime} 00^{\prime \prime} \mathrm{S}$ y Long. 73²1'39” W), también se observan algunas formas que podrían corresponder a glaciares rocosos, uno incluso con cubierta vegetacional parcial, así como arcos morrénicos, lo cual debe ser constatado.

\section{Conclusiones}

Todavía y a pesar de las investigaciones desarrolladas y en curso en la Cordillera de Los Andes de Chile, el conocimiento de la presencia de permafrost, sea insular, discontinuo o continuo, como de los glaciares rocosos, sean glacigénicos o criogénicos, es un tema que requerirá de mucha más dedicación y esfuerzo, lo internos, careciendo de formas indicadoras de actividad de empuje, como son surcos y cordones transversos y convexos (ridges $\&$ furrows).

Los datos básicos de los glaciares rocoso reconocidos en ambos valles del Parque se presentan en la tabla 7. 
aspecto este último que plantea interrogantes sobre las razones de su formación respecto de los argumentos climáticos.

Ello se condice con la existencia de glaciares rocosos más allá de las actuales zonificación establecidas y que, como se infiere de la contrastación entre antecedentes y resultados, falta aún mucho por saber sobre el real volumen de estas reservas y el impacto del cambio climático en ellos, dado lo observado en trabajos previos del autor en situaciones locales como el Glaciar Pirámide y el glaciar rocoso del Valle del Silencio entre otros, así como sobre su dinámica y posibles mecanismos de alimentación-fusión, lo cual tiene clara relación con la interacción entre la precipitación sólida, el incremento del radiative forcing, el calentamiento resultante y el rol de los diferentes espesores de las cubiertas morrénicas en tanto evolucionan de transmisor térmico a aislante térmico a partir de $\pm 3 \mathrm{~m}$ de potencia, dependiendo ello de la selección granulométrica y de la litología.

Por otra parte, en grandes volcanes del sur de Chile, como el Volcán Corcovado y el Melimoyu, llama la atención la manifestación de procesos evolutivos de glaciares blancos a glaciares rocosos en sus laderas de umbría, situación que solo habría sido detectada previamente en el Volcán Tronador, en ambas exposiciones.

Junto a ello, el reconocimiento de la existencia de glaciares rocosos en el Parque Nacional Torres del Paine, tanto en la cabecera del Valle del Francés como en el Valle del Silencio y por las características morfológicas que presentan, tales como lo irregular del manto morrénico y la generación de depresiones de colapso y lagunas, se puede considerar como una evidencia más del efecto concreto del incremento de las temperaturas en la zona sur y austral de Chile, así como de la tendencia de incremento decadal de las temperaturas medias anuales del sector, lo que refrenda el avance del clima mediterráneo hacia el sur de Chile.

\section{Bibliografía}

Aniya, M., Enomoto, H., Aoki, T., Matsumoto, T., Skvarca, P., Barcaza, G., ... Naruse, R. (2007) . Glaciological and geomorphological studies at Glaciar Exploradores, Hielo Patagónico Norte, and Glaciar Perito Moreno, Hielo Patagónico Sur, South America, during 2003-2005 (GRPP03-05). Bulletin of Glaciological Research, 24, 95-107. Recuperado de http:// www.seppyo.org/bgr/pdf/24/BGR24p95.pdf

Azócar, G. \& Brenning, A. (2010). Hydrological and geomorphological significance of rock glaciers in the dry Andes, Chile $\left(27^{\circ}-33^{\circ} \mathrm{S}\right)$. Permafrost and Periglacial Process, 21(1), 42-53. https://doi.org/10.1002/ ppp.669

Barsch, D. (July, 1978). Active rock glaciers as indicators for discontinuous alpine permafrost. An Example from the Swiss Alps. Trabajo presentado en Proceedings Third International Conf. on Permafrost. Edmonton, Alberta, Canada. Nat. Res. Council of Canada, Ottawa.

Barsch, D. (1996). Rockglaciers. Indicators for the present and former geoecology in high mountain environments. Springer, Berlin. https://doi.org/10.1007/978-3-642-80093-1

Bown, F. (2004). Cambios climáticos en la Región de Los Lagos y respuestas recientes del Glaciar Casa Pangue (41 $08^{\prime} \mathrm{S}$ ) (Tesis de Magíster inédita). Universidad de Chile, Santiago de Chile.

Bown, F., Rivera, A., \& Acuña, C. (2008). Recent glacier variations at the Aconcagua basin, central Chilean Andes. Annals of Glaciology 48, 43-48. https://doi. org/10.3189/172756408784700572

Brenning, A. (2003). La importancia de los glaciares de escombros en los sistemas geomorfológico e hidrológico de la Cordillera de Santiago: Fundamentos y primeros resultados. Revista de Geografia Norte Grande 30, 7-22. Recuperado de http://www.redalyc.org/html/300/30003002/ 
Brenning A. (2005). Geomorphological, hydrological and climatic significance of rock glaciers in the Andes of Central Chile (33-35 $\left.{ }^{\circ} \mathrm{S}\right)$. Permafrost and Periglacial Processes 16(3), 231-240. https://doi. org/10.1002/ppp.528

Brenning, A., Bodin, X., Trombotto, D., Ferrando, F., Azócar, G., Herrera, F., \& Hernández, J. (2009). Glaciares rocosos en Chile Semiárido. (Informe Técnico 2). Convenio Unidad de Gestión de Proyectos UC- DGA/MOP.

Brenning, A., Azócar, G., \& Bodin, X. (2010). Mapping and monitoring of rock glaciers in the Chilean Andes: a Progress Report. Trabajo presentado en The Third European Conference on Permafrost, EUCOP III, Svalvard. Norway. Resúmen recuperado de https://www.researchgate. net/publication/280848285_Mapping _ and monitoring of rock glaciers in the Chilean_Andes_a_progress_report_III European_Conference_on_Permafrost

Brenning, A., Bodin, X., Trombotto, D., Ferrando, F., Azócar, G., Herrera, F., \& Hernández, J. (2010). Glaciares rocosos en Chile Semiárido, Plan de Monitoreo (Informe Técnico 3). Convenio Unidad de Gestión de Proyectos UC-DGA/MOP.

Brenning, A., Long, S., \& Fieguth, P. (2012). Detecting rock glacier flow structures using Gabor filters and IKONOS imagery. Remote Sensing of Environment, 125, 227-237. https://doi.org/10.1016/j.rse.2012.07.005

Ferrando, F. (1996). Glaciares relictuales en el marco andino del semi-árido de Chile, IV Región: Análisis de caso. Trabajo presentado en Primer Taller Internacional de Geoecología de Montaña y Desarrollo Sustentable de los Andes del Sur. Universidad de Chile \& the United Nations University: Imp. WEISASOFT Ltda.

Ferrando, F. (2003a). Dynamic characteristics of rock glaciers from the Semiarid Andes of northern Chile. Trabajo presentado en Symposium on Mass Balance of Andean Glaciers \& First Mass Balance Workshop of Andean Glaciers. CECS, Valdivia, Chile.

Ferrando, F. (2003b). Aspectos conceptuales y genético-evolutivos de los glaciares rocosos: Análisis de caso en los Andes semiáridos de Chile. Revista IGM-Chile Terra Australis, 48, 43-74.

Ferrando, F. (2003c). Glaciares rocosos: Algunas comparaciones morfológicas entre Los Alpes occidentales y los Andes semiáridos de Chile. Trabajo presentado en el XXIII Congreso Nacional y VIII Internacional de Geografía de Chile. Universidad de La Serena, Chile.

Ferrando, F. (2012). Glaciar Pirámide: Características y evolución reciente de un glaciar cubierto: Evidencias del cambio climático. Investigaciones Geográficas, 44, 57-74.

Ferrando, F. (2014). Glaciar Pirámide: Glaciar rocoso subtipo cubierto y efectos del calentamiento en la Cordillera de Los Andes de Chile Central. En Gómez O., A; Salvador Franch, F; Oliva F., M; Salvá C., M. (eds.). Avances, métodos y técnicas en el estudio del periglaciarismo (pp.135 a 147). Barcelona, España: Publicacions i edicions de la Universitat de Barcelona.

Ferrando, F., Soto, M.V., Vieira, R., Lange, H., \& Quinteros, J. (2003). Permafrost en los Andes del Sur: Glaciares rocosos en la región semiárida de Chile y su importancia como recurso hídrico. Trabajo presentado en Anales $9^{\circ}$ Encuentro de Geógrafos de América Latina EGAL, Mérida, México.

Ferrando, F. Janke, J., \& Bellisario, A., (2015). Clasificación de Glaciares Rocosos de origen glacial. Trabajo presentado en Anales Sociedad Chilena de Ciencias Geográficas 2014, 33-41. Resumen recuperado de http:// sociedadchilenadecienciasgeograficas. cl/2014/wp-content/uploads/2014/10/ Anales-2014.pdf 
Fernández, H. y Ferrando, F. (2017). Glaciares rocosos en la Zona Semiárida de Chile: Relevancia de un recurso hídrico sin protección normativa. Cuadernos Geográficos de Colombia. (Sometido a la redacción)

Ferrando, F. \& Bellisario, A. (2017). Aportes del permafrost a la escorrentía en condiciones de sequía en una cuenca fluvial de los Andes occidentales extra tropicales de Chile Central, América del Sur: Caso del Río Putaendo, Región de Valparaíso, Chile. Anales Sociedad Chilena de Ciencias Geográficas 2016.

Janke, J., Bellisario,A., \& Ferrando, F. (2015). Classification of debris-covered glaciers and rock glaciers in the Andes of central Chile. Geomorphology, 241, 98-121. https://doi. org/10.1016/j.geomorph.2015.03.034

Lliboutry, L. (1956). Nieves y Glaciares de Chile: Fundamentos de Glaciología. Santiago de Chile: Editorial Universitaria.

Lliboutry, L., González O., \& Simken, J. (1958). Les Glaciers du Desert Chilien. Extrait des Comptes Rendues et Rapports. Asamblée Générale du Toronto 1957 (Gentbrugge 1958), IV, 291-300.

Marangunic, C. (1976). El Glaciar de Roca "Pedregoso", Río Colorado, V Región. En Actas del Primer Congreso Geológico Chileno. Santiago, Chile, Tomo I(Sección D), 71-80.

Marangunic, C. (1977). Inventario de Glaciares Hoya del Río Maipo. Santiago de Chile: Dirección General de Aguas, Ministerio de Obras Públicas, Gobierno de Chile.

Masiokas, M., Rivera, A., Espizúa, L., Villalba, R., Delgado S., \& Aravena, J.C. (2009). Glacier fluctuations in extratropical South America during the past 1000 years. Palaeogeography, palaeoclimatology, palaeoecology, 281(3-4), 242-268. https:// doi.org/10.1016/j.palaeo.2009.08.006
Ministerio de Obras Públicas, Dirección General de Aguas, Gobierno de Chile (MOP-DGA) (2009). Estrategia Nacional de Glaciares: Fundamentos. S.I.T. № 205.

Monnier, S. \& Kinnard, C. (2013) Internal structure and composition of a rock glacier in the Andes (upper Choapa valley, Chile) using borehole information and ground-penetrating radar. Annals of Glaciology, 54(64), 61-72. https://doi.org/10.3189/2013AoG64A107

Monnier S. \& Kinnard C. (2015a). Internal Structure and Composition of a Rock Glacier in the Dry Andes, Inferred from Groundpenetrating Radar Data and its Artefacts. Permafrost and Periglacial Processes, 26(4): 335-346. https://doi.org/10.1002/ppp.1846

Monnier S. \& Kinnard C. (2015b). Geomorphology, internal structure, and successive development of a glacier foreland in the semiarid Chilean Andes (Cerro Tapado, upper Elqui Valley, $30^{\circ} 08^{\prime}$ S., $69^{\circ} 55^{\prime}$ W.) - Reply to Discussion by D.C. Nobes. Geomorphology, 250, 461-463. https://doi. org/10.1016/j.geomorph.2015.02.010

Monnier S. \& Kinnard, C. (2015c). Reconsidering the glacier to rock glacier transformation problem: new insights from the Central Andes of Chile. Geomorphology, 238, 47-55. https://doi.org/10.1016/j. geomorph.2015.02.025

Nicholson, L., Marín, J., Lopez, D., Rabatel, A., Bown, F., \& Rivera, A. (2009). Glacier inventory of the upper Huasco valley, Norte Chico, Chile: glacier characteristics, glacier change and comparison with central Chile. Annals of Glaciology, 50(53), 111-118. https:// doi.org/10.3189/172756410790595787

Noveroy, C. (1987). Inventario de Glaciares de la hoya del río Mataquito (Dirección General de Aguas, Publicación Interna, EH 87/1). Santiago, Chile.

Paskoff, R. (1970). Le Chili Semiaride: Recherches Geomorphologiques. Bordeaux, France: Ed. Biscaye Fréres 
Payne, D. (1998). Climatic implications of rock glaciers in the arid Western Cordillera of the Central Andes. Glacial Geology \& Geomorphology, rp03.

Rivera, A. (1989). Inventario de glaciares entre las cuencas de los ríos Bio Bio y Petrohué. Su relación con el volcanismo activo: Caso del volcán Lonquimay. (Tesis de pregrado inédita). Universidad de Chile, Santiago de Chile.

Rivera, A. (2002). Inventario de Glaciares de Chile. Santiago de Chile: Laboratorio de Glaciología (Centro de Estudios Científicos del Sur y Universidad de Chile). [sitio web] Recuperado de http://www. glaciologia.cl/web/glaciologia_es/proyecto. php?idProyecto $=\&$ init $=$

Rivera,A. \& Casassa, G. (2004). Ice elevation, areal, and frontal changes of glaciers from National Park Torres del Paine, Southern Patagonia Icefield. Artic, Antarctic and Alpine Research, 36(4), 379-389. https://doi. org/10.1657/1523-0430(2004)036[0379:IE AAFC]2.0.CO;2

Rivera, A., Casassa, G., Acuña, C., \& Lange, H. (2000). Variaciones recientes de glaciares en Chile. Revista Investigaciones geográficas, 34, 25-52. https://doi. org/10.5354/0719-5370.2000.27709

Rivera, A., Bown, F., Mella, R., Wendt, J., Casassa, G., Acuña, C., ... Brock. B. (2006). Ice volumetric changes on active volcanoes in southern Chile. Annals of Glaciology, 43, 111-122. https://doi. org/10.3189/172756406781811970
Rivera, A., Benham, T., Casassa, G., Bamber, J., \& Dowdeswell, J. (2007). Ice elevation and areal changes of glaciers from the Northern Patagonia icefield, Chile. Global and Planetary Change, 59(1-4), 126-137. https:// doi.org/10.1016/j.gloplacha.2006.11.037

Santibañez, F. (2017). Estimación del área glaciarizada en la cuenca del Río Maipo mediante sensores remotos multiespectrales: confrontación con el inventario nacional de glaciares. (Tesis de pregrado inédita). Universidad de Chile. Santiago de Chile.

Soto, M. V., Ferrando, F., Vieira, R. (2002). Características Geomorfológicas de un sistema de Glaciares Rocosos y de su cuenca de sustentación en Chile semiárido. Investigaciones Geográficas 36, 1-16. https:// doi.org/10.5354/0719-5370.2002.27741

Ulloa, C., García, A., Amigo, G., \& Milana, J. P. (octubre, 2015). Línea base de la Criósfera para la cuenca del Río Copiapó. Trabajo presentado en el XIV Congreso Geológico Chileno. Recuperado de https://www. researchgate.net/publication/292059565

Vivero, S. (2008). Inventario de glaciares descubiertos de la cuenca del Rio Copiapó y variaciones recientes en sus frentes (Informe final de práctica profesional, Dirección General de Aguas DGA-MOP). Chile.

Wilgat, T., Kosik, A., \& Wojcirchowski, K. (1970). Hidrología de la Cuenca del Aconcagua. Selección de ejemplos: La Región del Alto Río Juncal. Informaciones Geográficas, años XVIII y XIX, número especial 1968-1969, 5-44. 